\title{
BMJ Open Waterpipe dependence in university students and effect of normative beliefs: a cross-sectional study
}

\author{
P Salameh, ${ }^{1}$ J Salamé, ${ }^{2}$ M Waked, ${ }^{3}$ B Barbour, ${ }^{4}$ N Zeidan, ${ }^{4}$ I Baldi ${ }^{5}$
}

To cite: Salameh $P$,

Salamé J, Waked M, et al. Waterpipe dependence in university students and effect of normative beliefs: a crosssectional study. BMJ Open 2014:4:e04378.

doi:10.1136/bmjopen-2013004378

- Prepublication history and additional material for this paper is available online. To view these files please visit the journal online (http://dx.doi.org/10.1136/ bmjopen-2013-004378).

Received 31 October 2013 Revised 17 December 2013 Accepted 10 January 2014

\section{CrossMark}

${ }^{1}$ Clinical \& Epidemiological Research Laboratory, Faculty of Pharmacy, Lebanese University, Hadath, Lebanon ${ }^{2}$ Charité-Universitätsmedizin University Hospital, Berlin, Germany

${ }^{3}$ Pulmonology Department, Saint Georges Hospital \& Faculty of Medicine,

Balamand University, Beirut, Lebanon

${ }^{4}$ Faculty of Public Health, Lebanese University, Fanar, Lebanon

${ }^{5}$ Laboratoire Santé Travail Environnement, Université Bordeaux Segalen, Bordeaux, France

Correspondence to Professor Pascale Salameh; psalameh@ul.edu.lb

\section{ABSTRACT}

Objectives: The objective of this study was to measure the correlates, including normative beliefs, associated with waterpipe (WP) and cigarette smoking prevalence and dependence.

Setting: A cross-sectional study was carried out using a proportionate cluster sample of Lebanese students in 17 public and private universities.

Participants: Of the 4900 distributed questionnaires, $3384(69.1 \%)$ were returned to the field worker. All available students during break times were approached, with no exclusion criteria.

\section{Primary and secondary outcome measures:}

sociodemographic variables, detailed active and passive smoking, in addition to items of the tobacco dependence scales were all evaluated.

Results: Correlates to WP smoking were studying in a private university (adjusted OR, aOR=1.50 (1.26 to 1.79); $p<0.001$ ) and ever smoking cigarettes $(\mathrm{aOR}=1.80(1.44$ to 2.26$) ; \mathrm{p}<0.001)$; friends' and societal influence were found on smoking behaviour and dependence. Although the role of parents was not visible in decreasing the risk of smoking WP, their protective influence seemed more important on WP dependence $(\beta=-1.09(-1.79$ to -0.28$) ; p<0.001)$, a behaviour that is considered more deleterious for health. Parents' and friends' disagreement with smoking had a protective effect on cigarette smoking and dependence $(\mathrm{aOR}<1 ; p<0.01)$, while thinking that idols and successful people smoke increased the risk of both cigarette smoking and dependence $(\mathrm{aOR}>1$; $p<0.01$ ).

Conclusions: In conclusion, WP smoking and dependence are influenced by parents' and friends' opinions, and idols' smoking status. Future research is necessary to further improve our understanding of motives for WP smoking and dependence.

\section{INTRODUCTION}

Waterpipe (WP) smoking is increasing in popularity, particularly among young people and university students. ${ }^{1-4} \mathrm{WP}$ is thought to contain toxic substances, similar to those contained in cigarette. ${ }^{5-6}$ It has been shown to increase the risk of several diseases, including

\section{Strengths and limitations of the study}

- This is the epidemiological first study exploring normative believes effect on waterpipe (WP) smoking in university students.

- This is the first study in the region concerning WP dependence in university students.

- The study was conducted over a large number of university students in Lebanon.

- Anonymity and non-traceability of participants increases the possibility of honest answers.

- The study showed that parents' opinion did not affect WP smokers, while it had a protective effect against WP dependence.

- The sample was not random, thus a selection bias could not be excluded.

- Information bias is also possible, because results were based on self-declared answers.

- The use of self-completed questionnaires may increase the risk of non-response to certain items.

- We have not taken into account all factors that may predict nicotine dependence.

- Qualitative studies could be useful to further explain the results we obtained.

chronic bronchitis, ${ }^{7}$ chronic obstructive pulmonary disease, ${ }^{8}$ lung cancer ${ }^{9}$ and other ailments. ${ }^{9}$

WP has also been demonstrated to contain nicotine, the substance responsible, at least partially, for addictive effects. ${ }^{10}{ }^{11}$ It has been associated with an identified dependence effect similar to what could be found with cigarette, in addition to a social factor that adds to its potential addictive effect ${ }^{12}$; as expected, WP dependence per se was associated with higher smoking frequency and higher risk of health effects among WP smokers, as compared to non-dependent WP smokers. ${ }^{78}$

The structure of the WP-associated dependence concept was shaped by the development and validation of a specific score, the Lebanese Waterpipe Dependence Scale-11 (LWDS-11). ${ }^{13}$ The score included items of 'smoking to please others' and 'smoking for pleasure'; two items shown to have high importance in late adolescence and young 
adulthood. ${ }^{14}$ The main motives for WP smoking are declared to be socialising, relaxation, pleasure and entertainment; this was suggested in a systematic review with qualitative data synthesis of numerous studies. Peer pressure, fashion and curiosity were additional motives declared by university students, while expression of cultural identity seemed an additional motive for people in the Middle East. ${ }^{14} 15$

Among young cigarette smokers, students' perceptions of smoking among the successful/elite and disapproval by parents/peers were independently associated with susceptibility to smoking. ${ }^{16}$ In parallel, some epidemiological studies were conducted to evaluate these effects in case of WP smoking, and showed that parents' tolerance of WP smoking, peer WP smoking and the idea of popularity were main motives for this behaviour. ${ }^{17-19}$

For cigarette dependence, earlier onset of at least once a month cigarette smoking, heavier overall consumption and peers' smoking were associated with higher nicotine dependence in young Saudi students. ${ }^{20}$ Moreover, parental smoking restrictions may have the potential to impede adolescent progression to adult smoking behaviour by reducing smoking rates and nicotine dependence. ${ }^{21}$

To our knowledge, very few studies have been conducted regarding WP dependence, particularly in the Middle Eastern region, while normative beliefs have hardly been addressed.

Thus, although we may know what drives WP smoking in youngsters, no studies have ever quantitatively assessed the magnitude of normative beliefs' influences among university smokers on WP dependence, a more deleterious behaviour for health. The objective of this study was to measure the correlates, including normative beliefs, associated with WP and cigarette prevalence and dependence.

\section{METHODS}

\section{Population and sampling}

A cross-sectional study was carried out using a proportionate cluster sample of Lebanese students in the public and private universities. A list of universities in Lebanon, provided by the Center for Pedagogic Researches, was used to adjust the sample size. ${ }^{22}$ A sample size of at least 3000 individuals was targeted to allow for adequate power for bivariate and multivariate analysis to be carried out on several factors; this sample size is powerful enough for any factor prevalence and association OR above 2.

The administrative offices of most universities in Lebanon that were approached did not allow drawing a random sample of their enrolled students to participate in the study; they did not provide us with the lists of students and permission was not granted to enter classrooms and search for students nominatively. Thus, our research group had to work with a non-random sample of students outside their classes. Students were approached on campus during break times between courses by a field worker.

The latter explained the study objectives to the student; and after obtaining oral consent, the student was handed the anonymous and self-administered questionnaire. On average, the questionnaire was completed by participants within approximately $20 \mathrm{~min}$. At the end of the process, the completed questionnaires were placed in closed boxes and sent for data entry. During the data collection process, the anonymity of the students was guaranteed, to allow for lower information bias. Of the 4900 distributed questionnaires, 3384 $(69.1 \%)$ were returned to the field worker; the sample included students from 17 universities (the public university of Lebanon that accounts for half the university students in Lebanon and 16 private ones which account together for the other half). Further methodological details are presented in more details elsewhere. ${ }^{3}$

\section{Questionnaires}

The questionnaire used in this study had several parts, including the sociodemographic part, and a detailed active and passive smoking history, in addition to items of the tobacco dependence questions. Socioeconomic status of students was defined using their mean monthly income per family divided by the number of family members; afterwards, quartiles were calculated and used to classify individuals into four levels.

Current WP smoking was defined as smoking at least one WP per month, while current cigarette smoking was defined as smoking at least one cigarette per day. For cigarette dependence, we used the Young Adults Cigarette Dependence (YACD) scale, ${ }^{23}$ and for WP dependence, the LWDS- $11,{ }^{13}$ both of which were developed by our team for the Lebanese population. The YACD has been developed for university students; it comprises 16 items, loading over six factors: nicotine dependence, craving intensity; positive reinforcement and negative reinforcement. ${ }^{23}$ The LWDS-11 comprises 11 items, loading on a four-factors structure in adults: nicotine physiological dependence, positive reinforcement, negative reinforcement and psychological craving $^{13}$; its validity and reliability had to be confirmed in this young adults' sample before use.

Moreover, questions on normative beliefs were taken from a study performed on cigarette smokers by Primack $e t a l^{16}$ measures of students' perceptions of smoking among successful people, cool people and idols and disapproval by parents and peers were evaluated by Likert scale questions: 0 indicated strongly disagree; 1 , disagree; 2 , maybe; 3 , agree; 4 , strongly agree. These were further collapsed in bivariate analysis into yes (3 and 4$)$, maybe (2) and no (0 and 1$)$.

\section{Statistical analysis}

Data entry was performed by independent lay persons who were unaware of the objectives of the study; these were postgraduate students who were not involved in 
data collection process. Data cleaning was performed by researchers, and a sample of 50 questionnaires was completely checked for errors. The error rate was lower than $1 \%$; thus, data entry was considered adequate.

Statistical analysis was performed using SPSS software, V.13.0. A p value of 0.05 was considered significant. Cluster sampling effect was taken into account according to Rumeau-Rouquette $e t a l^{24}$. Data weighting was performed according to the total number of students per university, as described by the Center for Educational Research and Development-Lebanese Ministry of Education. ${ }^{22}$

To confirm the LWDS-11 validity and reliability in the study sample, an exploratory factor analysis was first performed with its items, after ensuring sample adequacy with the Kaiser-Meyer-Olkin (KMO) index, and Bartlett's $\chi^{2}$ test of sphericity. Factors were extracted using the principal component analysis. Items were retained if they loaded 0.4 or more on factors. Since factors were found to be correlated, we chose to perform a promax rotation with Kaiser normalisation. Afterwards, reliability analysis was performed by Cronbach's $\alpha$ values for factors and the total scale.

Comparison of means was performed using analysis of variance in bivariate analysis, with Bonferoni correction on post hoc tests. Non-parametric tests were used in case of small subgroups (Kruskal-Wallis and Wilcoxon tests, respectively).

To decrease confounding bias, we performed multivariate analyses: multiple regressions were carried out using a stepwise backward method, after ensuring sample adequacy, linearity of the model, residual normality and non-collinearity of retained items (variance inflation factor $<2$ ). We took WP dependence and cigarette dependence as dependent variables in respective models, using sociodemographic characteristics normative beliefs and other forms of smoking (ie, WP smoking among cigarette smokers and cigarette smoking among WP smokers) as independent variables. Both dependent variables were normally distributed. A $p$ value $<0.05$ was considered significant; missing data were not replaced for this analysis due to their low percentage $(<10 \%)$.

For indicative purposes, we also conducted multiple logistic regressions, using current WP and cigarette smoking as dichotomous dependent variables, respectively and sociodemographic characteristics, other forms of smoking and normative beliefs as independent variables. After ensuring non-collinearity and sampling adequacy by Hosmer-Lemeshow test, we reported adjusted ORs (aORs).

\section{RESULTS}

Among 3384 university students, 779 (23\%) reported that they were current WP smokers, and $649(19.2 \%)$ that they were current cigarette smokers. Among WP smokers, $760(97.6 \%)$ answered to all questions of the LWDS-11 scale, while among cigarette smokers, 595
(91.7\%) answered to the complete YACD scale questions.

\section{Description of the current WP and cigarettes smokers' subsamples}

Among WP smokers $(\mathrm{n}=779)$, the mean number of WP smoked per week was $4.12(\mathrm{SD}=4.76)$, while the mean duration of smoking was 6.96 years $(\mathrm{SD}=2.33)$. The mean age of the first WP intake was 16.46 years $(\mathrm{SD}=2.43)$. Among WP smokers, $35 \%$ declared having the intention to stop smoking later, and $20 \%$ declared wanting to stop smoking immediately. Moreover, $28.7 \%$ ever tried to stop smoking but did not succeed. LWDS mean was 10.23, its median was 9 , and SD 6.03. The minimum was zero and maximum 30 . Its distribution was almost normal, with a skewness of 0.1.

Among cigarette smokers $(n=649)$, the mean number of cigarettes smoked per day was $17.23(\mathrm{SD}=9.3)$, while the mean duration of smoking was 4.32 years $(\mathrm{SD}=2.25)$. The mean age of the first cigarette intake was 15.89 years $(\mathrm{SD}=2.35)$. Among cigarette smokers, $43.2 \%$ declared having the intention to stop smoking later, and $27.2 \%$ declared wanting to stop smoking immediately. Moreover, $48.7 \%$ ever tried to stop smoking but did not succeed. YACD mean was 13.92, its median was 14.04 and SD 5.95 . The minimum was 2.5 and maximum 29. Its distribution was almost normal, with a skewness of 0.6.

We note that 234 (6.9\% of the total students sample) were currently dual smokers of both cigarettes and WP. They constituted $36.4 \%$ of cigarette smokers and $30 \%$ of current WP smokers.

\section{Validity and reliability of the LWDS-11 in Lebanese university students}

The KMO measure of sampling adequacy was 0.79 $(p<0.001)$. All communalities were higher than 0.35 , and the extracted principal component sums of squared loadings explained $66.58 \%$ of the total variance.

The Promax rotation with Kaiser normalisation gave a four-factors solution with the following pattern (table 1): factor 1 (physiological dependence; $33.14 \%$ of the variance explained), factor 2 (psychological craving; $13.08 \%$ of the variance explained), factor 3 (negative reinforcement; $11.59 \%$ of the variance explained) and factor 4 (positive reinforcement; $8.78 \%$ of the variance explained). Reliability measured by Cronbach's $\alpha$ for the total score was 0.77 . We note that the structure is highly similar to the one found in adults, with one difference: the income item which originally loaded on physiological dependence, now loaded on psychological craving. For the rest of psychometric properties, the scale gave almost identical results.

Factors were correlated with each other: factor 1 correlated with factors $2 \quad\left(\mathrm{r}_{12}=0.42\right), 3 \quad\left(\mathrm{r}_{13}=0.39\right)$ and 4 $\left(\mathrm{r}_{14}=0.09\right)$, factor 2 correlated with factors $3\left(\mathrm{r}_{23}=0.40\right)$ and $4\left(\mathrm{r}_{24}=0.02\right)$ and factor 3 correlated with factor 4 $\left(\mathrm{r}_{34}=0.14\right)$.

WP and cigarette dependence variation with sociodemographic characteristics. 
Table 1 Validity and reliability of the LWDS-11 among university students of Lebanon

\begin{tabular}{|c|c|c|c|c|}
\hline Items & $\begin{array}{l}\text { Factor } 1 \\
\text { Physiological } \\
\text { dependence }\end{array}$ & $\begin{array}{l}\text { Factor } 2 \\
\text { Psychological } \\
\text { craving }\end{array}$ & $\begin{array}{l}\text { Factor } 3 \\
\text { Negative } \\
\text { reinforcement }\end{array}$ & $\begin{array}{l}\text { Factor } 4 \\
\text { Positive } \\
\text { reinforcement }\end{array}$ \\
\hline $\begin{array}{l}\text { How many times were you able to stay } \\
7 \text { days without smoking waterpipe? }\end{array}$ & 0.877 & & & \\
\hline $\begin{array}{l}\text { How many days could you stay without } \\
\text { smoking waterpipe? }\end{array}$ & 0.871 & & & \\
\hline $\begin{array}{l}\text { Number of smoked waterpipes per } \\
\text { week? }\end{array}$ & 0.798 & & & \\
\hline $\begin{array}{l}\text { Would you smoke waterpipe even if } \\
\text { you are ill/bedridden? }\end{array}$ & & 0.836 & & \\
\hline $\begin{array}{l}\text { Are you ready not to eat in exchange } \\
\text { for a waterpipe? }\end{array}$ & & 0.827 & & \\
\hline Would you smoke waterpipe alone? & & 0.547 & & \\
\hline $\begin{array}{l}\text { How much of your income are you } \\
\text { ready to pay for waterpipe smoking? }\end{array}$ & & 0.426 & & \\
\hline Smokes waterpipe to relax his nerves & & & 0.868 & \\
\hline $\begin{array}{l}\text { Smokes waterpipe to improve his } \\
\text { morale }\end{array}$ & & & 0.862 & \\
\hline $\begin{array}{l}\text { Smokes waterpipe to please others } \\
\text { (conviviality) }\end{array}$ & & & & 0.910 \\
\hline Smokes waterpipe for pleasure & & & & 0.573 \\
\hline Cronbach's $\alpha$ reliability measure & 0.806 & 0.659 & 0.671 & 0.527 \\
\hline
\end{tabular}

In table 2, we first present the characteristics of the whole sample of university students, for descriptive purposes. WP dependence was significantly higher among widows or divorced individuals, and among individuals who have higher numbers of smokers at home (table 2). However, cigarette dependence was higher in males, lower socioeconomic status individuals, the 20-21 years age class, the public university and among individuals who have higher numbers of smokers at home; it was also lower in South Lebanon versus other regions (table 2).

\section{Normative beliefs influence on WP and cigarette dependence}

WP dependence was higher in case individuals believed that successful people smoke, rich people smoke, their idols smoke; it was lower in case individuals knew it was important for their parents, their friends and people of their age that they do not smoke (table 3). Nearly similar results were found for cigarette dependence, except for an additional significantly higher dependence in case individuals believed that cool people smoked, and a lower trend for significance for the peers' opinion about smoking (table 3).

\section{Multivariate analysis of WP and cigarette current smoking}

Studying in a private university and ever smoking cigarettes were correlated to current WP smoking; moreover, thinking that successful and cool people smoke increased the odds of being a current WP smoker, while having friends who disagree with smoking was correlated with lower WP smoking (table 4). However, being male sex, not single, higher age, residing in Mount or North Lebanon, studying in a private university and ever smoking WPs increase the odds of being a current cigarette smoker; thinking that successful people or idols smoke was correlated to increased cigarette smoking probability, while having parents who disagree with smoking was correlated with lower cigarette smoking (table 4).

\section{Multivariate analysis of WP and cigarette dependence}

In multiple regression of WP dependence, parents and friends' opinion against smoking were inversely associated while belief that idols smoke were positively associated with WP dependence; moreover, higher age class was also associated with higher WP dependence (table 4). For cigarette dependence, parents' opinion against smoking was strongly and inversely associated, while the perception that idols, rich and successful people smoked were positively associated with cigarette dependence (table 4).

We note that performing the analysis among dual smokers gave similar results of dependence correlates for both WP and cigarettes with normative beliefs, except for a visible association of dual dependence with male gender versus females $(\mathrm{OR}=5.10 \quad(2.83 ; 9.19)$; $\mathrm{p}<0.001$; other results not shown).

\section{DISCUSSION}

In this study, we found that correlates of current WP smoking were studying in a private university (representing access to money), ever smoking cigarettes and clear friends' and societal influence, as found in other studies. $^{17-19} 25$ Moreover, friends' disagreement with 
Table 2 LWDS-11 and YACD means in different sociodemographic categories of smokers

\begin{tabular}{|c|c|c|c|c|c|}
\hline Characteristic $^{\star \star}$ & Total $n=3384$ & LWDS-11 Mean (SD) & p Value & YACD (SD) & p Value \\
\hline Sex & & & 0.082 & & 0.006 \\
\hline Male & $1980(58.5 \%)$ & $10.62(6.21)$ & & $14.22(5.95)$ & \\
\hline Female & $1399(41.3 \%)$ & $9.86(5.84)$ & & $12.70(5.98)$ & \\
\hline Marital status & & & $0.006^{\star}$ & & 0.664 \\
\hline Married & $115(3.4 \%)$ & $10.00(4.85)$ & & $14.76(7.65)$ & \\
\hline Single & $3243(95.8 \%)$ & $10.19(6.02)$ & & $13.84(5.99)$ & \\
\hline Widow or divorced & $9(0.3 \%)$ & $17.50(6.17)$ & & $11.5(0.00)$ & \\
\hline Socioeconomic status quartiles $†$ & & & 0.35 & & 0.051 \\
\hline Quartile 1 & $736(21.7 \%)$ & $9.69(5.51)$ & & $15.61(6.09)$ & \\
\hline Quartile 2 & $746(22.0 \%)$ & $10.67(5.78)$ & & $14.11(6.11)$ & \\
\hline Quartile 3 & $632(18.7 \%)$ & $9.68(6.04)$ & & $13.51(5.65)$ & \\
\hline Quartile 4 & $746(22.1 \%)$ & $10.47(6.90)$ & & $13.70(5.95)$ & \\
\hline Age classes (years) & & & $0.053 \dagger$ & & $<0.001^{*}$ \\
\hline $17-19$ & $958(28.3 \%)$ & $9.42(5.86)$ & & $11.69(5.37)$ & \\
\hline $20-21$ & $1424(42.1 \%)$ & $10.75(5.88)$ & & $14.93(5.90)$ & \\
\hline 22 and more & $982(29.0 \%)$ & $10.14(6.36)$ & & $13.27(6.07)$ & \\
\hline Private university & $1754(51.8 \%)$ & $10.21(6.03)$ & 0.422 & $13.33(5.88)$ & 0.005 \\
\hline Public university & $1630(48.2 \%)$ & $9.86(6.07)$ & & $14.77(6.09)$ & \\
\hline Region & & & 0.135 & & $<0.0019$ \\
\hline Beyrouth & $526(15.5 \%)$ & $10.72(6.62)$ & & $13.21(5.99)$ & \\
\hline Mount Lebanon & $1606(47.5 \%)$ & $9.55(6.03)$ & & $14.05(5.89)$ & \\
\hline North Lebanon & $505(14.9 \%)$ & $10.91(4.87)$ & & $15.47(6.43)$ & \\
\hline South Lebanon & $474(14.0 \%)$ & $10.55(6.21)$ & & $9.99(3.47)$ & \\
\hline Bekaa plain & $221(6.5 \%)$ & $9.95(6.07)$ & & $12.28(6.31)$ & \\
\hline Number of smokers at home & & & $<0.001^{*}$ & & $<0.001 \S$ \\
\hline No smokers & $896(26.5 \%)$ & $9.00(5.51)$ & & $11.98(5.19)$ & \\
\hline One smoker & $1022(30.2 \%)$ & $8.87(5.65)$ & & $11.68(5.44)$ & \\
\hline Two smokers & $722(21.3 \%)$ & $10.21(5.75)$ & & $12.46(5.45)$ & \\
\hline Three and more & 604 (17.8\%) & $12.28(6.42)$ & & $16.21(5.92)$ & \\
\hline
\end{tabular}

*All two by two differences were significant.

†Difference significant between the first two categories.

†Difference between first and third categories was significant. §Difference significant between third category and others is significant.

$\S$ Difference between the third category and others is significant.

TSouth Lebanon significantly different from other regions.

${ }^{\star *}$ ANOVA was used in all comparisons, with Bonferoni adjustment; Kruskall-Wallis non parametric test was used for marital status due to

small subgroup size, with further Wilcoxon two-by-two comparison.

$\dagger+$ Socioeconomic status of students was defined using their mean monthly income per family divided by the number of family members;

afterwards, quartiles were calculated and used to classify individuals into four levels; we note that 524(15.5\%) gave no valid answer for socioeconomic status.

ANOVA, analysis of variance; LWDS-11, Lebanese Waterpipe Dependence Scale-11; YACD, Young Adults Cigarette Dependence.

smoking decreased WP dependence: in the latter case, smoking for conviviality during social gatherings is absent, and this component of positive reinforcement and cue for smoking in many individuals would be expected to affect individuals' dependence to $\mathrm{WP}^{13}$ Idols' smoking of university students increased the risk of WP dependence, which may also be considered the reverse side of the medal of the societal influence.

Age increased the risk of WP dependence; this may be explained by the establishment of this habit with time during life in university and more frequent exposure, or due to its possible insidious nature of dependence that may only appear after repeated exposures. The nature of WP dependence installation may differ from cigarette dependence that seems to install in young people after only a few cigarettes. ${ }^{26-28}$ Indeed, Asfar et $a l^{29}$ have shown the existence of beginners and established WP smokers, the latter being less willing to quit WP smoking and more hooked on the habit.

Although the role of parents was not visible in decreasing the risk of smoking WP, their protective influence seemed more important on WP dependence; the latter behaviour has been shown to be more deleterious for health. ${ }^{78}$ A social tolerance of WP smoking by parents may explain this finding, ${ }^{17}$ who may intervene with their offspring in case of dependence only; additional studies are necessary to evaluate whether parents are able to differentiate between occasional WP smokers and dependent WP smokers among their children.

As for cigarette smoking, numerous sociodemographic factors were found to correlate with the behaviour: male sex, high age, married/widow/divorced marital status, residing in Mount and North Lebanon, studying in a private university and ever smoking WP. Parents' 
Table 3 LWDS-11 and YACD means bivariate analysis with societal influence

\begin{tabular}{|c|c|c|c|c|}
\hline Characteristic* & LWDS-11 mean (SD) & p Value & YACD mean (SD) & p Value \\
\hline Successful people smoke & & $<0.001 \dagger$ & & $<0.001 \ddagger$ \\
\hline Yes & $9.93(5.80)$ & & $12.81(5.91)$ & \\
\hline Maybe & $9.61(5.61)$ & & $12.50(5.39)$ & \\
\hline No & $11.92(6.90)$ & & $16.43(5.66)$ & \\
\hline Cool people smoke & & 0.163 & & $0.002 \S$ \\
\hline No & $9.93(6.30)$ & & $12.79(5.91)$ & \\
\hline Maybe & 9.91 (5.99) & & $13.88(5.95)$ & \\
\hline Yes & $10.79(5.91)$ & & $14.76(5.94)$ & \\
\hline Rich people smoke & & $0.002 \dagger$ & & $<0.001 \ddagger$ \\
\hline No & $10.04(6.21)$ & & $12.71(5.89)$ & \\
\hline Maybe & $9.55(5.60)$ & & $13.72(5.89)$ & \\
\hline Yes & $11.79(5.86)$ & & $16.69(5.35)$ & \\
\hline My idols smoke & & $0.030 \S$ & & $<0.001 \ddagger$ \\
\hline No & $10.03(6.09)$ & & $12.49(5.78)$ & \\
\hline Maybe & $9.90(5.69)$ & & $12.86(5.96)$ & \\
\hline Yes & $11.43(6.58)$ & & $16.77(5.65)$ & \\
\hline For my parents, it is important not to smoke & & $<0.001 \dagger$ & & $<0.001 \ddagger$ \\
\hline No & $13.25(6.88)$ & & $16.99(5.24)$ & \\
\hline Maybe & $10.28(6.17)$ & & $16.18(5.51)$ & \\
\hline Yes & $9.78(5.78)$ & & $12.57(5.77)$ & \\
\hline For my friends, it is important not to smoke & & $<0.001 \rrbracket$ & & $<0.001^{* *}$ \\
\hline No & $12.22(6.50)$ & & $15.49(5.79)$ & \\
\hline Maybe & $10.00(5.65)$ & & $13.26(5.52)$ & \\
\hline Yes & $9.34(5.81)$ & & $13.05(6.19)$ & \\
\hline For people of my age, it is important not to smoke & & 0.009† & & 0.088 \\
\hline No & $11.33(6.31)$ & & $14.53(6.04)$ & \\
\hline Maybe & 9.37 (5.69) & & $13.45(5.70)$ & \\
\hline Yes & $9.79(6.03)$ & & $13.39(6.06)$ & \\
\hline \multicolumn{5}{|l|}{$\begin{array}{l}\text { *ANOVA was used in all comparisons, with Bonferroni ad } \\
\text { †All two by two differences were significant. } \\
\text { †Difference was not significant between categories } 1 \text { and } \\
\text { §Difference between first and third categories was signifi } \\
\text { IDifference significant between the first two categories. } \\
\text { **Difference was not significant between categories } 2 \text { and }\end{array}$} \\
\hline
\end{tabular}

disagreement with smoking had a protective effect on cigarette smoking and dependence, while thinking that idols and successful people smoke increased the risk of both cigarette smoking and dependence, similar to other researchers' findings. ${ }^{16}{ }^{30}$ Friends influence was also visible, as with other studies. ${ }^{16} 30-31$

The idea of dual smoking deserves to be noted: smoking one kind of tobacco is associated with higher odds of smoking the other, and being dependent on one kind of tobacco increases the risk of dependence on other kinds. Similar results were found among British university students, where cigarette smoking was a major motive for WP smoking ${ }^{32}$ and among US students, where the majority of WP smokers were also cigarette smokers. ${ }^{33}$ The fact that dependence to cigarettes and to WP includes nicotine dependence components clearly explains this finding. ${ }^{11} 3435$ This may also biologically be confirmed with results found by Rastam et $a l,{ }^{36}$ where cigarette and WP both decrease nicotine craving symptoms in dual smokers, and WP may interact with cigarette smoking cessation.
One more conceptual issue deserves our attention: the LWDS-11 was of adequate validity and reliability in university students of Lebanon; the structure was highly similar to the one found in adults, ${ }^{13}$ with one difference: the income item which originally loaded on physiological dependence in adults, now loaded more adequately on psychological craving among students. One explanation could be that may adults adapt their smoking frequency and agree to pay portions of their incomes according to usual physiological nicotine needs, while younger university students would be ready to pay higher portions of their incomes only in case of extreme psychological craving (which is considered a more compelling urge than usual physiological dependence). Access to money being more limited for university students than for working adults may clarify this issue; in parallel, it is worth noting that in the YACD, the money item had also loaded on the psychological craving factor, not on the nicotine dependence factor. ${ }^{23}$ Additional qualitative studies would be necessary to confirm this finding; nevertheless, the LWDS-11 
Table 4 Multivariate analysis tobacco use and dependence

\begin{tabular}{|c|c|c|c|c|}
\hline Binomial-dependent variable & $\begin{array}{l}\text { Logistic regression } \\
\text { Independent variables }\end{array}$ & Adjusted OR & $(95 \%$ of $\mathrm{Cl})$ & p Value \\
\hline \multirow[t]{7}{*}{ Current waterpipe smoking ${ }^{\star}, \dagger$} & Studying in a private university & 1.50 & (1.26 to 1.79$)$ & $<0.001$ \\
\hline & Successful people smoke & 1.46 & (1.29 to 1.65$)$ & $<0.001$ \\
\hline & Cool people smoke & 1.25 & (1.12 to 1.39$)$ & $<0.001$ \\
\hline & Friends think it is important not to smoke & 0.86 & (0.78 to 0.96$)$ & 0.006 \\
\hline & Ever smoking cigarettes & 1.80 & (1.44 to 2.26$)$ & $<0.001$ \\
\hline & Female sex vs. male & 1.00 & (0.83 to 1.21$)$ & 0.969 \\
\hline & Higher age class & 1.01 & (0.90 to 1.13$)$ & 0.871 \\
\hline \multirow[t]{12}{*}{ Current cigarette smoking ${ }^{*}, \dagger$} & Female sex vs. male & 0.24 & (0.19 to 0.29$)$ & $<0.001$ \\
\hline & Other than single marital status & 2.63 & (1.20 to 5.76$)$ & 0.016 \\
\hline & Higher age class & 1.37 & (1.19 to 1.57$)$ & $<0.001$ \\
\hline & Mount Lebanon vs. Beirut & 1.37 & (1.03 to 1.82$)$ & 0.029 \\
\hline & North Lebanon vs. Beirut & 1.46 & (1.00 to 2.13$)$ & 0.053 \\
\hline & South Lebanon vs. Beirut & 0.48 & (0.30 to 0.78$)$ & 0.003 \\
\hline & Bekaa plain vs. Beirut & 0.61 & (0.36 to 1.02$)$ & 0.057 \\
\hline & Studying in a private university & 1.96 & (1.58 to 2.43$)$ & $<0.001$ \\
\hline & Successful people smoke & 1.75 & (1.52 to 2.01$)$ & $<0.001$ \\
\hline & My idols smoke & 1.13 & (0.99 to 1.30$)$ & 0.074 \\
\hline & $\begin{array}{l}\text { Parents think it is important not to } \\
\text { smoke }\end{array}$ & 0.81 & (0.70 to 0.93$)$ & 0.002 \\
\hline & Ever smoking waterpipes & 1.56 & (1.22 to 1.99$)$ & $<0.001$ \\
\hline Continuous-dependent variable & $\begin{array}{l}\text { Multiple regression } \\
\text { Independent variables }\end{array}$ & $\begin{array}{l}\text { Adjusted } \\
\text { standardised }\end{array}$ & $\begin{array}{l}\text { Adjusted } \beta \text { values } \\
(95 \% \mathrm{Cl})\end{array}$ & p Value \\
\hline \multirow[t]{5}{*}{ LWDS-11 among WP smokers } & $\begin{array}{l}\text { Parents think it is important not to } \\
\text { smoke }\end{array}$ & -0.124 & $-1.09(-1.79$ to -0.28$)$ & 0.002 \\
\hline & Friends think it is important not to smoke & -0.117 & $-0.87(-1.46$ to -0.28$)$ & 0.004 \\
\hline & My idols smoke & 0.079 & $0.63(0.06$ to 1.21$)$ & 0.031 \\
\hline & Higher age class & 0.069 & $0.58(-0.01$ to 1.17$)$ & 0.053 \\
\hline & Female sex vs. Male & -0.019 & $-0.23(-1.09$ to 0.64$)$ & 0.609 \\
\hline \multirow[t]{6}{*}{$\begin{array}{l}\text { YACD among cigarette } \\
\text { smokers§, } †\end{array}$} & $\begin{array}{l}\text { Parents think it is important not to } \\
\text { smoke }\end{array}$ & -0.24 & $-1.87(-2.45$ to -1.29$)$ & $<0.001$ \\
\hline & My idols smoke & 0.16 & $1.18(0.56$ to 1.80$)$ & $<0.001$ \\
\hline & Rich people smoke & 0.13 & 0.97 (0.37 to 1.57$)$ & 0.002 \\
\hline & Successful people smoke & 0.08 & $0.56(-0.02$ to 1.14$)$ & 0.059 \\
\hline & Higher age class & 0.07 & $0.58(-0.06$ to 1.21$)$ & 0.075 \\
\hline & Female sex vs. male & -0.06 & $-0.77(-1.77$ to 0.24$)$ & 0.136 \\
\hline
\end{tabular}

*Performed on whole university students sample; conditions for sample adequacy satisfied; stepwise backward model; all other variables were not retained in the model. Gender and age class were forced in the models.

†Variables included in all models: marital status, socioeconomic classes, region of residence, private university (versus public), successful people smoke, cool people smoke, rich people smoke, my idols smoke, parents think it is important not to smoke, friends think it is important not to smoke, people of the same age think it is important not to smoke, smoking other type of tobacco. Gender and age class were forced in the models.

$\ddagger R=0.255$; adjusted $R^{2}=0.065$; stepwise model; Variance Inflation Factor $(V I F)<2$; residuals are normal; all other variables were not retained in the model. Gender and age class were forced in the models.

$\S R=0.426$; sdjusted $R^{2}=0.175$; stepwise model; VIF $<2$; residual are normal; all other variables were not retained in the model. Gender and age class were forced in the models.

LWDS-11, Lebanese Waterpipe Dependence Scale-11; WP, waterpipe; YACD, Young Adults Cigarette Dependence.

demonstrated adequate validity and reliability, and could thus be used for the current study.

\section{Limitations of the study}

Our study, as with any, has its limitations: a selection bias could have been possible since the sample is not a random sample and may not be representative of the young adults and students' population in Lebanon. This non-random sampling could lead to an overrepresentation of students who skip classes and may have higher risky behaviours, such as smoking. There could also be a possibility of respondent and information bias, since the results of our study are based on a self-administered questionnaire. Despite the fact that we ensured anonymity and confidentiality of all data that has been collected, respondents may have underreported some of their behaviours that lead to missing values. Furthermore, we have not taken into account all factors that may predict nicotine dependence, since it has been shown that background factors, psychological characteristics and genetic variation in nicotinic cholinergic receptors contribute independently or interactively 
to smoking initiation and to severity of nicotine dependence in young people. ${ }^{37}$ We suggest that further research be conducted taking into account these limitations; we also suggest prospective studies to thoroughly evaluate the effect of parents and friends on future smoking behaviours, in addition to qualitative research that can explore the knowledge, attitudes and values behind these behaviours.

\section{CONCLUSION}

In conclusion, WP smoking and dependence are influenced by parents' and friends' opinions, and idols' smoking status; these results suggest the potential possibility of establishing peer education and help parents advising their young offspring about the importance of non-smoking WP. Future research is necessary to further improve our understanding of motives for WP smoking and dependence.

Contributors PS, JS, MW, BB, NZ and IB made equal contributions to the study design, data collection, analysis of results, drafting and reviewing of the manuscript.

Funding This project was funded by the Lebanese-French cooperation programme CEDRE.

Competing interests None.

Ethics approval The IRB of the Lebanese University waived the need for approval because this was an observational study with no traceability of participants.

Provenance and peer review Not commissioned; externally peer reviewed.

Data sharing statement No additional data are available.

Open Access This is an Open Access article distributed in accordance with the Creative Commons Attribution Non Commercial (CC BY-NC 3.0) license, which permits others to distribute, remix, adapt, build upon this work noncommercially, and license their derivative works on different terms, provided the original work is properly cited and the use is non-commercial. See: http:// creativecommons.org/licenses/by-nc/3.0/

\section{REFERENCES}

1. Chaaya M, El-Roueiheb $\mathrm{Z}$, Chemaitelly $\mathrm{H}$, et al. Argileh smoking among university students: a new tobacco epidemic. Nicotine Tob Res 2004;6:457-63.

2. Waked M, Salameh P, Aoun Z. Water-pipe (Narguile) Smokers in Lebanon: a pilot study. East Mediterr Health J 2009;15:432-42.

3. Salameh P, Jomaa L, Issa C, et al. The Lebanese National Conference for Health in University (LNCHU) study group. Assessment of health risk behaviours among university students: a cross-sectional study in Lebanon. Int J Adolesc Youth 2012a:1-14. http://dx.doi.org/10.1080/02673843.2012.733313

4. El-Roueiheb Z, Tamim H, Kanj M, et al. Cigarette and waterpipe smoking among Lebanese adolescents, a cross-sectional study, 2003-2004. Nicotine Tob Res 2008;10:309-14.

5. Cobb CO, Shihadeh A, Weaver MF, et al. Waterpipe tobacco smoking and cigarette smoking: a direct comparison of toxicant exposure and subjective effects. Nicotine Tob Res 2011;13:78-87.

6. Eissenberg T, Shihadeh A. Waterpipe tobacco and cigarette smoking: direct comparison of toxicant exposure. Am J Prev Med 2009;37:518-23.

7. Salameh P, Waked M, Khayat G, et al. Waterpipe smoking and dependence are associated with chronic bronchitis: a case control study. East Mediterr Health J 2012b;18:996-1004.

8. Salameh $\mathrm{P}$, Khayat $\mathrm{G}$, Waked $\mathrm{M}$, et al. Waterpipe smoking and dependence are associated with chronic obstructive pulmonary disease: a case-control study. Open Epidemiol J 2012c;5:36-44
9. Akl EA, Gaddam S, Gunukula SK, et al. The effects of waterpipe tobacco smoking on health outcomes: a systematic review. Int $J$ Epidemiol 2010;39:834-57.

10. Aoun Z, Salameh P, Waked M. Saliva cotinine and exhaled carbon monoxide in real life waterpipe smokers. Inhal Toxicol 2007;19:771-7.

11. Salameh $P$, Aoun Z, Waked M. Saliva cotinine and exhaled carbon monoxide in real life narghile (waterpipe) smokers: a post hoc analysis. Tob Use Insights 2009;2:1-10.

12. Hammal F, Mock J, Ward KD, et al. A pleasure among friends: how narghile (waterpipe) smoking differs from cigarette smoking in Syria. Tob Control 2008;17:e3.

13. Salameh P, Waked M, Aoun Z. Narguileh smoking: construction and validation of the LWDS-11 dependence scale. Nicotine Tob Res 2008;10:148-59.

14. Harakeh Z, Vollebergh WA. The impact of active and passive peer influence on young adult smoking: an experimental study. Drug Alcohol Depend 2012;121:220-3.

15. Akl EA, Jawad M, Lam WY, et al. Motives, beliefs and attitudes towards waterpipe tobacco smoking: a systematic review. Harm Reduct J 2013;10:12.

16. Primack B, Switzer G, Dalton M. Improving measurement of normative beliefs involving smoking among adolescents. Arch Pediatr Adolesc Med 2007;161:434-9.

17. Sabahy AR, Divsalar K, Bahreinifar S, et al. Waterpipe tobacco use among Iranian university students: correlates and perceived reasons for use. Int J Tuberc Lung Dis 2011;15:844-7.

18. Roohafza $\mathrm{H}$, Sadeghi $\mathrm{M}$, Shahnam $\mathrm{M}$, et al. Perceived factors related to cigarette and waterpipe (ghelyan) initiation and maintenance in university students of Iran. Int $J$ Public Health 2011;56:175-80.

19. Amin TT, Amr MA, Zaza BO, et al. Harm perception, attitudes and predictors of waterpipe (shisha) smoking among secondary school adolescents in Al-Hassa, Saudi Arabia. Asian Pac J Cancer Prev 2010;11:293-301.

20. Guo HJ, McGee R, Reeder T, et al. Smoking behaviours and contextual influences on adolescent nicotine dependence. Aust N Z $J$ Public Health 2010;34:502-7.

21. Ditre JW, Coraggio JT, Herzog TA. Associations between parental smoking restrictions and adolescent smoking. Nicotine Tob Res 2008;10:975-83.

22. Center for Educational research and development, Beirut, Lebanon. [List of Universities in Lebanon]. http://www.crdp.org/ CRDP

23. Salameh $P$, Jomaa L, Farhat $G$, et al. The Lebanese National Conference for Health in Universities Study Group. The Young Adults' Cigarette Dependence (YACD) Score: an improved tool for cigarette dependence assessment in university students. Addict Behav 2013;38:2174-9.

24. Rumeau-Rouquette C, Breart G, Padieu R. Méthodes en Epidémiologie: Echantillonnage, investigations, analyse. Paris: Flammarion Editions, 1985:71-82.

25. Al-Lawati JA, Muula AS, Hilmi SA, et al. Prevalence and determinants of waterpipe tobacco use among adolescents in Oman. Sultan Qaboos Univ Med J 2008;8:37-43.

26. DiFranza JR, Rigotti NA, McNeill AD, et al. Initial symptoms of nicotine dependence in adolescents. Tob Control 2000;9:313-19.

27. Scragg R, Wellman RJ, Laugesen M, et al. Diminished autonomy over tobacco can appear with the first cigarettes. Addict Behav 2008;33:689-98.

28. Ursprung WW, DiFranza JR. The loss of autonomy over smoking in relation to lifetime cigarette consumption. Addict Behav 2010;35:14-18.

29. Asfar T, Ward KD, Eissenberg T, et al. Comparison of patterns of use, beliefs, and attitudes related to waterpipe between beginning and established smokers. BMC Public Health 2005;5:19.

30. Odukoya OO, Odeyemi KA, Oyeyemi AS, et al. Determinants of smoking initiation and susceptibility to future smoking among school-going adolescents in Lagos state, Nigeria. Asian Pac J Cancer Prev 2013;14:1747-53.

31. Liao Y, Huang Z, Huh J, et al. Changes in friends' and parental influences on cigarette smoking from early through late adolescence. J Adolesc Health 2013;53:132-8.

32. Jackson D, Aveyard P. Waterpipe smoking in students: prevalence, risk factors, symptoms of addiction, and smoke intake. Evidence from one British university. BMC Public Health 2008;8:174

33. Ward KD, Eissenberg T, Gray JN, et al. Characteristics of US waterpipe users: a preliminary report. Nicotine Tob Res 2007;9:1339-46. 
34. Hudmon KS, Marks JL, Pomerleau CS, et al. A multidimensional model for characterizing tobacco dependence. Nicotine Tob Res 2003;5:655-64.

35. Heatherton TF, Kozlowski LT, Frecker RC, et al. The Fagerström Test for nicotine dependence: a revision of the Fagerström Tolerance Questionnaire. Br J Addict 1991;86:1119-27.
36. Rastam S, Eissenberg T, Ibrahim I, et al. Comparative analysis of waterpipe and cigarette suppression of abstinence and craving symptoms. Addict Behav 2011;36:555-9.

37. Greenbaum L, Kanyas K, Karni O, et al. Why do young women smoke? I. Direct and interactive effects of environment, psychological characteristics and nicotinic cholinergic receptor genes. Mol Psychiatry 2006;11:312-22, 223. 